\title{
The PK-Eye: A Novel In Vitro Ocular Flow Model for Use in Preclinical Drug Development
}

\author{
SAHAR AWWAD, ${ }^{1,2}$ ALASTAIR LOCKWOOD, ${ }^{1,2}$ STEVE BROCCHINI, ${ }^{1,2}$ PENG T. KHAW ${ }^{1}$ \\ ${ }^{1}$ National Institute for Health Research (NIHR) Biomedical Research Centre at Moorfields Eye Hospital NHS Foundation Trust and UCL \\ Institute of Ophthalmology, London EC1V 9EL, United Kingdom \\ ${ }^{2}$ UCL School of Pharmacy, London WC1N 1AX, United Kingdom
}

Received 13 February 2015; revised 8 April 2015; accepted 8 April 2015

Published online 24 June 2015 in Wiley Online Library (wileyonlinelibrary.com). DOI 10.1002/jps.24480

\begin{abstract}
A 2-compartment in vitro eye flow model has been developed to estimate ocular drug clearance by the anterior aqueous outflow pathway. The model is designed to accelerate the development of longer-acting ophthalmic therapeutics. Dye studies show aqueous flow is necessary for a molecule injected into the vitreous cavity to clear from the model. The clearance times of proteins can be estimated by collecting the aqueous outflow, which was first conducted with bevacizumab using phosphate-buffered saline in the vitreous cavity. A simulated vitreous solution was then used and ranibizumab $(0.5 \mathrm{mg})$ displayed a clearance time of $8.1 \pm 3.1$ days, which is comparable to that observed in humans. The model can estimate drug release from implants or the dissolution of suspensions as a first step in their clearance mechanism, which will be the rate-limiting step for the overall resident time of a candidate dosage form in the vitreous. A suspension of triamcinolone acetonide (Kenalog ${ }^{\circledR}$ ) $(4.0 \mathrm{mg}$ ) displayed clearance times spanning $26-28$ days. These results indicate that the model can be used to determine in vitro-in vivo correlations in preclinical studies to develop long-lasting therapeutics to treat blinding diseases at the back of the eye. (c) 2015 The Authors. Journal of Pharmaceutical Sciences published by Wiley Periodicals, Inc. and the American Pharmacists Association J Pharm Sci 104:3330-3342, 2015
\end{abstract}

Keywords: Intraocular fluid flow; in vitro/in vivo correlations (IVIVC); in vitro model; pharmacokinetics; proteins; protein delivery; intraocular drug suspension; ocular drug delivery; intravitreal injection

\section{INTRODUCTION}

Prolonging therapeutic levels of a drug within the vitreous to treat blinding diseases is one of the most important goals in ophthalmic drug development. Intravitreal (IVT) injections of therapeutic proteins and the use of steroid implants in the vitreous are currently the best clinical methods to achieve prolonged exposure in the back of the eye. With increased life expectancy and an aging population, more people will require treatment for longer periods to manage blinding conditions that would otherwise rapidly progress.

Therapeutic biologics registered for ophthalmic use by IVT injection comprise a PEGylated-aptamer (Pegaptanib), antibody fragment (ranibizumab), and a Fc fusion (alfibercept). ${ }^{1}$ These medicines bind to VEGF and are administered by IVT injection every 1-2 months. Although IVT injections are a costly, invasive procedure that is associated with a low risk for vision threatening complications, ${ }^{2}$ many health systems around the world cannot cope with the increasing demands for IVT injection of the current anti-VEGF treatments, ${ }^{3,4}$ even when administered every 1-2 months. The increased know-

Correspondence to: Peng T. Khaw (Telephone: +44 207608 6887; Fax: +44 207608 6887; E-mail: p.khaw@ucl.ac.uk); Steve Brocchini (Telephone: +44 207 753 5802; Fax: +44 207753 5942; E-mail: steve.brocchini@ucl.ac.uk)

Journal of Pharmaceutical Sciences, Vol. 104, 3330-3342 (2015)

(C) 2015 The Authors. Journal of Pharmaceutical Sciences published by Wiley

Periodicals, Inc. and the American Pharmacists Association

This is an open access article under the terms of the Creative Commons Attribution-NonCommercial License, which permits use, distribution and reproduction in any medium, provided the original work is properly cited and is not used for commercial purposes. ledge of the molecular mechanisms involved in blinding ocular diseases $^{5,6}$ will continue to drive the development of proteinbased medicines, ${ }^{1}$ which tend to be potent and have a rapid onset of action. This will further drive the development ${ }^{7-11}$ of longer-lasting IVT injection dosage forms such as implants that require less frequent administration.

Mass exchange within the eye is dominated by the aqueous that is secreted into the vitreous from the ciliary body (2.0 $2.5 \mu \mathrm{L} / \mathrm{min}) .{ }^{12-16}$ The vast majority of this aqueous passes the anterior hyaloid membrane and flows into the front of the eye (anterior chamber) to then leave the eye via trabecular and uveoscleral pathways. ${ }^{14-17}$ Drug elimination from the vitreous occurs by (1) the aqueous outflow into the anterior chamber and (2) permeation through the retina via retinal-choroid-sclera (RCS) pathways. ${ }^{14,18}$ Therapeutic proteins clear predominantly through the anterior route because they are high-molecularweight, charged molecules. ${ }^{7,19-23}$

Proteins have longer half-lives (i.e., days to weeks) $)^{6,7,20,24,25}$ in the vitreous than $\mathrm{RCS}^{26}$ permeable molecules (e.g., lipophilic molecules $\leq 500 \mathrm{Da}$ ), which generally are a matter of hours. ${ }^{18,27,28}$ Reasons for this include (1) lower molecular weight permeable molecules diffuse more rapidly in the vitreous than proteins, ${ }^{18,24,27,28}$ (2) the surface area of the retina is large compared to the anterior hyaloid membrane, and (3) permeable molecules can clear via several routes through the RCS (e.g., passive diffusion, active transport, binding to melanin, loss to conjuctival lymphatics and episcleral veins, and metabolism). ${ }^{18}$ In vitro cell permeation models have been developed to evaluate RCS permeability. ${ }^{29}$ It is thought that the physicochemical properties of a drug can often be used to predict RCS permeability. ${ }^{18,29-31}$ 
Little has been reported to develop an in vitro model that accounts for the aqueous flow ${ }^{32}$ to estimate clearance times for molecules that exit the eye predominantly via the anterior route through the front of the eye. Preclinical pharmacokinetic research for new ophthalmic preparations is dominated by the use of animal models. There are a multitude of anatomical differences between animal models and human eyes (e.g., aqueous flow, vitreous volumes, diffusion pathways). ${ }^{28,33-35}$ Young laboratory animals with an intact vitreous structure are often used, but much is still not understood about the vitreous ${ }^{36}$ between species, and animal models do not account for the variability and age-related differences of the human vitreous. ${ }^{24,30,37,38}$ Correlating results from the literature can be complicated because different experimental techniques are often used to obtain PK data for each species. ${ }^{18}$ The formation of antidrug antibodies (ADAs) also results in accelerated clearance rates, ${ }^{39}$ making it impossible to accurately evaluate candidate therapeutic proteins. ${ }^{40-43}$ ADAs can also cause nonspecific inflammation to compromise efficacy. ADA formation is not predictive of the human immunological response and remains an intractable problem that delays development of humanized protein therapeutics. ${ }^{44}$

The use of in vitro models has been important to develop and optimize many dosage forms including pulmonary (deposition), percutaneous (diffusion), and oral (dissolution) preparations. ${ }^{45-48}$ These models are also used to establish in vitro-in vivo correlations and extrapolations (IVIVC and IVIVE), ${ }^{49-53}$ and for quality control. ${ }^{54,55}$ For longer-acting ophthalmic preparations to be developed, preclinical candidates must display extended half-lives while under the influence of the aqueous flow within the eye. To address this need, we have developed an in vitro, two-compartment model scaled to human dimensions with aqueous flow designed to mimic the total aqueous mass transfer through the anterior route. The model (called the PK-Eye) is specifically designed to mimic the intraocular aqueous outflow to estimate (1) the clearance of therapeutic proteins, (2) the dissolution of drug suspensions, and (3) the release profiles of implants from the vitreous cavity. The design and flow properties of the in vitro model are described and then the model was used to estimate the intraocular residence times of ranibizumab, bevacizumab, and triamcinolone acetonide (TA) suspension, which were compared with published data from in vivo studies in animals and humans.

\section{MATERIALS AND METHODS}

\section{Materials}

Kenalog ${ }^{\circledR} \quad(40 \mathrm{mg} / \mathrm{mL})$ was purchased from Squibb. Bevacizumab (Avastin ${ }^{\circledR}, 25 \mathrm{mg} / \mathrm{mL}$; Genentech, South San Francisco, California) and ranibizumab (Lucentis ${ }^{\circledR}, 10 \mathrm{mg} / \mathrm{mL}$; Genentech, South San Francisco, California) were obtained from the pooled remaining contents of vials that had been used clinically. Sodium hyaluronate (solubility: $5.0 \mathrm{mg} / \mathrm{mL} ; 1.8 \mathrm{MDa}$ ) was purchased from Aston Chemicals (Aylesbury, UK) and agar (solubility: $15.0 \mathrm{mg} / \mathrm{mL}$ ) was obtained from Fluka Analytical (Gillingham, Dorset, UK). Dye (Coomassie Brilliant Blue, MW $=825.97 \mathrm{~g} / \mathrm{mol}$ ) was used to validate flow in the model. Visking dialysis membrane tubing (MWCO of 12-14 kDa) was purchased from Medicell International Ltd. (London, UK). Bovine serum albumin (BSA) was obtained from Sigma-Aldrich. A 16channel Ismatec peristaltic pump (Michael Smith Engineers
Ltd., Woking, Surrey, UK) was used to generate fluid flow into the PK-Eye. UV measurements were analyzed using Hitachi U-2800A spectrometer and a Wallac Victor2 1420 plate reader. HPLC was conducted using a Agilent 1200 series (Agilent, Wokingham, Berkshire, UK) equipped with Chemstation software (Agilent, Wokingham, Berkshire, UK) using a reversephase Synergi Polar-RP Phenomenex $4 \mu \mathrm{m}, 15 \mathrm{~cm}$ column.

\section{Methods}

\section{Design of the PK-Eye Flow Model}

Efforts to develop the model were focused at the outset (1) to have the anterior and posterior cavities to be a similar size as in the human eye and (2) to use an aqueous inflow that mimics the aqueous outflow in humans. The model comprises two plastic pieces that are secured together with four screws (Fig. 1). The overall dimensions and volumes of the posterior $(4.2 \mathrm{~mL})$ and anterior $(0.2 \mathrm{~mL})$ cavities of the model are comparable to that of the human eye (Table 1). Several prototypes of the model were evaluated (Table 2) to best mimic the mass transfer caused by aqueous outflow. The prototyping efforts listed in Table 2 were focused to design a model that was both simple to fabricate and to use. It was found that a single inlet port ( $1.5 \mathrm{~mm} \mathrm{ID)} \mathrm{with}$ a flow of $2.0 \mu \mathrm{L} / \mathrm{min}^{15}$ was the most practical way to mimic aqueous flow in this model. The aqueous inlet port was placed in the vitreous cavity near the membrane barrier. An injection port was placed at the top of the vitreous cavity. A widely available dialysis membrane (MWCO 12-14 kDa) was fixed between the posterior and anterior cavities (Fig. 1). This membrane was used to provide a barrier to the anterior cavity for solubilized molecules residing in the posterior cavity. For outflow, a single outlet port in the anterior cavity extended upwards from the model to provide a small amount of backpressure. This was used to avoid the formation of air bubbles and to maintain the total liquid volume within the model.

\section{PK-Eye Dye Validation Studies}

The inlet port was connected with tubing (1.5 mm ID) to a dispensing pump that provided aqueous (phosphate-buffered saline, PBS) inflow of $2.0 \mu \mathrm{L} / \mathrm{min}$. Dye (Coomassie Brilliant Blue) was injected $(100 \mu \mathrm{L}, 1.2 \mathrm{mM})$ into the posterior cavity of the model in one experiment and then in the anterior cavity in another experiment to compare the effects of flow at ambient temperature. For the non-flow experiments, the model was full of liquid with its ports blocked with parafilm to replicate no flow. Images were obtained using a digital camera at various time points to visualize the dye clearance from the model.

\section{Simulated Vitreous and Viscosity Measurements}

Agar (0.4 g) and hyaluronic acid (HA) (0.5 g) were each separately mixed in $100 \mathrm{~mL}$ of stirred hot water. ${ }^{57}$ The agar solution was boiled to completely solubilize the agar. After boiling, the hot agar solution was mixed with HA and stirred to give a homogenous mixture to which a few drops of $0.02 \%$ sodium azide were added. The solution was left to cool for $24 \mathrm{~h}$ to ambient temperature $\left(\sim 21^{\circ} \mathrm{C}\right)$ and formed into a gel-like consistency. Viscosity $(n=3)$ was measured using an AR $1000-\mathrm{N}$ Rheolyst Rotational TA rheometer (TA Instruments, Elstree, $\mathrm{UK}$ ) at $25^{\circ} \mathrm{C}$. Approximately $2.0-3.0 \mathrm{~mL}$ of simulated vitreous was pipetted onto the rheometer plate while avoiding both over and under filling of the rheometer plate. The rheometer plate was washed with distilled water before each measurement and 


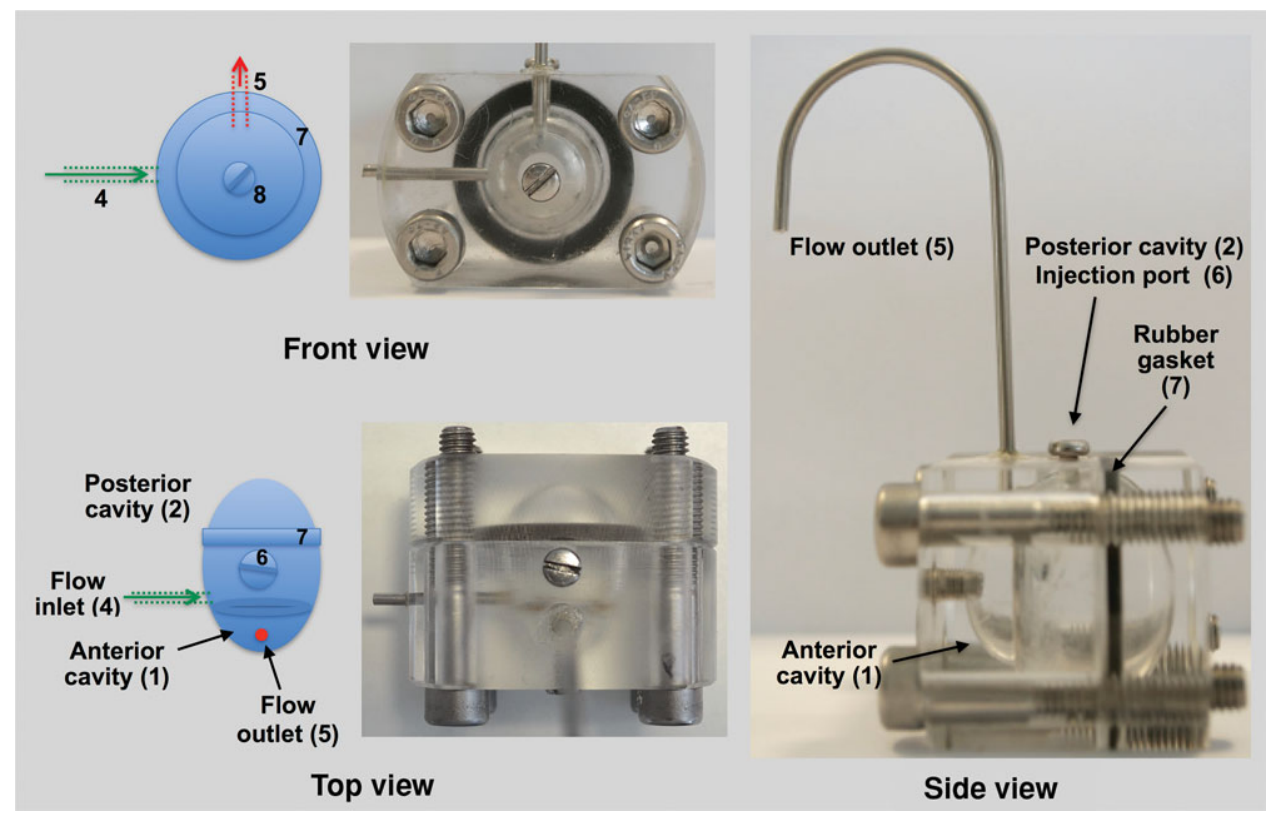

Figure 1. Top, front and side images of the PK-Eye model used in these studies. The model comprises two plastic pieces that are held together with four screws with a fitted rubber washer (7) between the two pieces to seal the posterior cavity and to prevent leakage. A membrane (3) separates the anterior (1) and posterior (2) cavities, which have a volume of $200 \mu \mathrm{L}$ and $4.2 \mathrm{~mL}$, respectively. The inlet port (4) allows flow immediately posterior to the membrane (3). The inlet port was connected with plastic tubing (1.5 mm internal diameter) to a 16-channel Ismatec peristaltic pump to produce a flow rate of $2.0 \mu \mathrm{L} / \mathrm{min}$ of PBS, $\mathrm{pH} 7.4$ with $0.02 \%$ sodium azide. Aqueous outflow is collected from the anterior cavity at a single outlet port (5), which is elevated to about $3.0 \mathrm{~cm}$ to provide a small amount of back pressure to maintain a full internal volume within the model. The inner diameter of the inlet and outlet ports was $1.0-1.5 \mathrm{~mm}$.

Table 1. Average Human Eye Dimensions Versus the Dimensions of the PK-Eye Model Used in This Study

\begin{tabular}{lccc}
\hline Dimensions & Anatomy & $\begin{array}{c}\text { Average } \\
\text { Human Eye }\end{array}$ & $\begin{array}{c}\text { PK-Eye } \\
\text { Model }\end{array}$ \\
\hline Length $(\mathrm{mm})$ & Cornea vertical length & 11.0 & 9.0 \\
& Cornea horizontal length & 12.0 & 9.0 \\
Volume (mL) & Posterior cavity & $3.9-5.0$ & 4.2 \\
& Anterior cavity & 0.2 & 0.2 \\
\hline
\end{tabular}

the temperature was kept constant $\left(25^{\circ} \mathrm{C}\right.$.) The pseudo-linear viscoelastic region was determined using an oscillatory stress sweep over a broad torque range (1-10,000 uN.m). The pseudoviscosity profile was obtained using a continuous flow test and an oscillatory time sweep was used to monitor whether the properties of the simulated vitreous changed over time.

\section{Protein Clearance Studies}

To coat the model with albumin solution, it was filled with $0.1 \% \mathrm{BSA}$ solution and after securing the injection port, the model was incubated at $37^{\circ} \mathrm{C}$ for $12 \mathrm{~h}$ ( $n=3$ for each experiment). The model was then disassembled and washed with water and refilled with PBS ( $\mathrm{pH} 7.4$ ). To examine the effects of vitreous viscosity, the simulated vitreous was added to the posterior cavity by syringe and PBS was added to the anterior cavity through its injection port. Ranibizumab $(0.5 \mathrm{mg})$ and bevacizumab $(1.25 \mathrm{mg})$ were injected $(50 \mu \mathrm{L})$ into the center of the vitreal cavity and sampling was generally accomplished by collection at the outflow port. Samples were stored at $4^{\circ} \mathrm{C}$ prior to analysis for protein content by the Bradford assay.

\section{TA (Kenalog $\left.{ }^{\circledR}\right)$ Clearance Studies}

The posterior cavity of the model was filled with the appropriate media (PBS, pH 7.4 or simulated viscous vitreous). PBS ( $\mathrm{pH}$ 7.4) was then added to the anterior chamber. The aqueous flow $(2.0 \mu \mathrm{L} / \mathrm{min})$ was started and the model was placed into a preheated oil bath at $37^{\circ} \mathrm{C}$. Temperature was maintained using a probe connected to the hotplate heater. After approximately $2 \mathrm{~h}$ of heating the model, TA (Kenalog ${ }^{\circledR}, 4.0 \mathrm{mg}$ in $100 \mu \mathrm{L}$ ) was injected into the posterior segment of the model. Sampling was accomplished daily by replacing the vial used to collect the outflow from the anterior cavity. Samples were stored at $4{ }^{\circ} \mathrm{C}$ and then analyzed by HPLC (254 $\mathrm{nm})$.

\section{Quantification of Drug Release}

The Bradford assay was used to determine protein concentration. Samples and standards $(40 \mu \mathrm{L})$ were evaluated in triplicate using 96-well plates and mixed with Bradford Ultra reagent $(110 \mu \mathrm{L})$. Plates were incubated for $10 \mathrm{~min}$ at room temperature and absorbance at $590 \mathrm{~nm}$ was measured using a plate reader. The calibration curve $\left(R^{2}\right.$ value of 0.99$)$ was made using a solution of antibody $(100 \mu \mathrm{g} / \mathrm{mL})$ that was serially diluted (PBS, pH 7.4) to $10 \mu \mathrm{g} / \mathrm{mL}$. Average measurements for blank $(0 \mu \mathrm{g} / \mathrm{mL}$ of antibody) were subtracted from standards and unknown samples. The concentrations of unknown samples were estimated based on the standard curve. Samples from each time point was evaluated in triplicate $(n=3)$ and the mean and standard deviation were determined. 
Table 2. Summary of PK-Eye Prototype Development

\begin{tabular}{|c|c|c|c|c|c|}
\hline \multirow[b]{2}{*}{ Prototype } & \multicolumn{2}{|c|}{ Ports } & \multirow[b]{2}{*}{ Vitreous (mL) } & \multirow[b]{2}{*}{ Design Information } & \multirow[b]{2}{*}{ Observations During Validation } \\
\hline & In & Out & & & \\
\hline $\mathrm{A}$ & 1 & 1 & 5.6 & $\begin{array}{l}\text { A spherical globe made of } \\
\text { polyacrylate plastic }\end{array}$ & $\begin{array}{l}\text { The volume was too large } \\
\text { compared with the human eye }\end{array}$ \\
\hline B & 2 & 1 & 4.2 & $\begin{array}{l}\text { Volume was adjusted to match } \\
\text { the average value reported in } \\
\text { human eyes }\end{array}$ & Cavity lacked spherical shape \\
\hline $\mathrm{C}$ & 2 & 4 & 4.2 & $\begin{array}{l}\text { Incorporation of anterior }(0.2 \\
\mathrm{mL}) \text { and posterior cavities } \\
(4.2 \mathrm{~mL})\end{array}$ & $\begin{array}{l}\text { Could not maintain a gel to } \\
\text { water interface between } \\
\text { posterior and anterior cavities }\end{array}$ \\
\hline $\mathrm{D}$ & 2 & 10 & 4.2 & $\begin{array}{l}\text { Fit cavity separating membrane } \\
\text { and increase outlet ports }\end{array}$ & $\begin{array}{l}\text { Unequal and insufficient flow in } \\
\text { each port observed }\end{array}$ \\
\hline $\mathrm{E}$ & 2 & 4 & 4.2 & $\begin{array}{l}\text { Reduce the number of outlet } \\
\text { ports }\end{array}$ & $\begin{array}{l}\text { Input port diameters too large } \\
\text { and too far away from the } \\
\text { cavity separating membrane }\end{array}$ \\
\hline $\mathrm{F}$ & 4 & 4 & 4.2 & $\begin{array}{l}\text { Move input ports to replicate } \\
\text { ciliary body location and flow }\end{array}$ & $\begin{array}{c}\text { Inadequate and inconsistent } \\
\text { flow from each outlet port }\end{array}$ \\
\hline $\mathrm{G}$ & 4 & 1 & 4.2 & $\begin{array}{l}\text { Incorporation of new outlet port } \\
\text { in the anterior cavity }\end{array}$ & $\begin{array}{l}\text { Too difficult to maintain an } \\
\text { accurate flow rate using four } \\
\text { inlet ports }\end{array}$ \\
\hline $\mathrm{H}$ & 1 & 1 & 4.2 & $\begin{array}{l}\text { One inlet to replicate ciliary } \\
\text { body flow }\end{array}$ & $\begin{array}{l}\text { Much more practical to use than } \\
\text { with two inlet ports }\end{array}$ \\
\hline
\end{tabular}

The prototype that was used for these studies reported herein is $\mathrm{H}$.

The concentration of TA $\left(\right.$ Kenalog $\left.^{\circledR}\right)$ was determined by HPLC with UV detection $(254 \mathrm{~nm})$ using methanol-water $(70: 30, \mathrm{v} / \mathrm{v})$ as the mobile phase. A retention time of approximately 3.7 min was observed. The injection volume was $10 \mu \mathrm{L}$ with a flow rate of $1.0 \mathrm{~mL} / \mathrm{min}$ and a run time of $10 \mathrm{~min}$. The calibration curve ( $R^{2}$ value of 0.97$)$ was made starting with a TA suspension ( $1 \mathrm{mg} / \mathrm{mL}$ ) that was serially diluted using PBS to $0.39 \mu \mathrm{g} / \mathrm{mL}$.

\section{Data Analysis}

All results are presented as the mean and standard deviation, and data were plotted using OriginPro. Half-lives $\left(t_{1 / 2}\right)$ was calculated according to the best fitting model in OriginPro. First-order kinetic rate constants $(k)$ were derived from the monoexponential curve and half-lives were calculated using the equation: $0.693 / k$. The rate constants $(k)$ of zero-order release profiles were calculated as concentration-time and half-lives were calculated from initial concentration $[A]$ using $[A] / 2 k$.

\section{RESULTS AND DISCUSSION}

\section{Dye Experiments to Illustrate Flow Properties of the Model}

Dye studies were conducted to illustrate the need for flow and compartmentalization of the model. With the aqueous inlet flow set at $2.0 \mu \mathrm{L} / \mathrm{min}$, Coomassie blue dye was injected $(100 \mu \mathrm{L}$, $1.2 \mathrm{mM}$ ) into the anterior cavity (Fig. 2). The amount of dye used was in large excess to what can be administered in an in vivo experiment by either injection or the use of eye drops. The dye cleared through the outlet port with only a trace amount being observed to migrate into the posterior cavity at about $24 \mathrm{~h}$ after injection (Fig. 2). In a second experiment, the dye was injected into the posterior cavity. With aqueous inflow $(2.0 \mu \mathrm{L} / \mathrm{min})$, the dye cleared from the posterior cavity into the anterior cavity

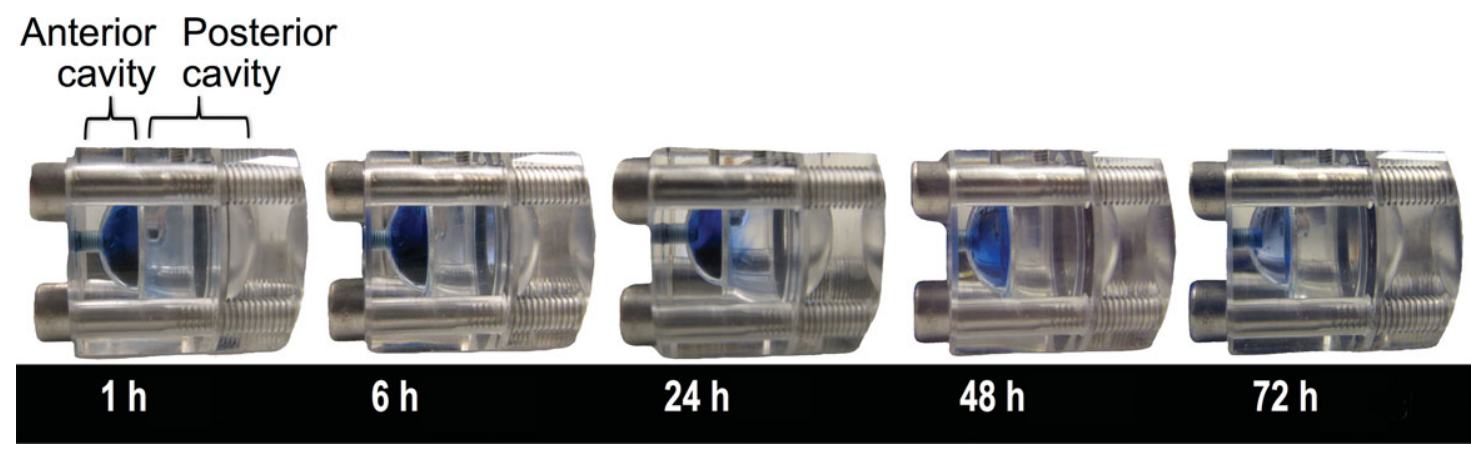

Figure 2. Injection of coomassie blue dye $(100 \mu \mathrm{L}, 1.2 \mathrm{mM})$ into anterior cavity of the model. The aqueous inflow into the posterior cavity was $2.0 \mu \mathrm{L} / \mathrm{min}$. Only a trace amount of the dye can be seen to migrate into the posterior cavity (slight blue colouration in the posterior cavity at $24 \mathrm{~h}$ ) as the dye clears from the anterior cavity. 

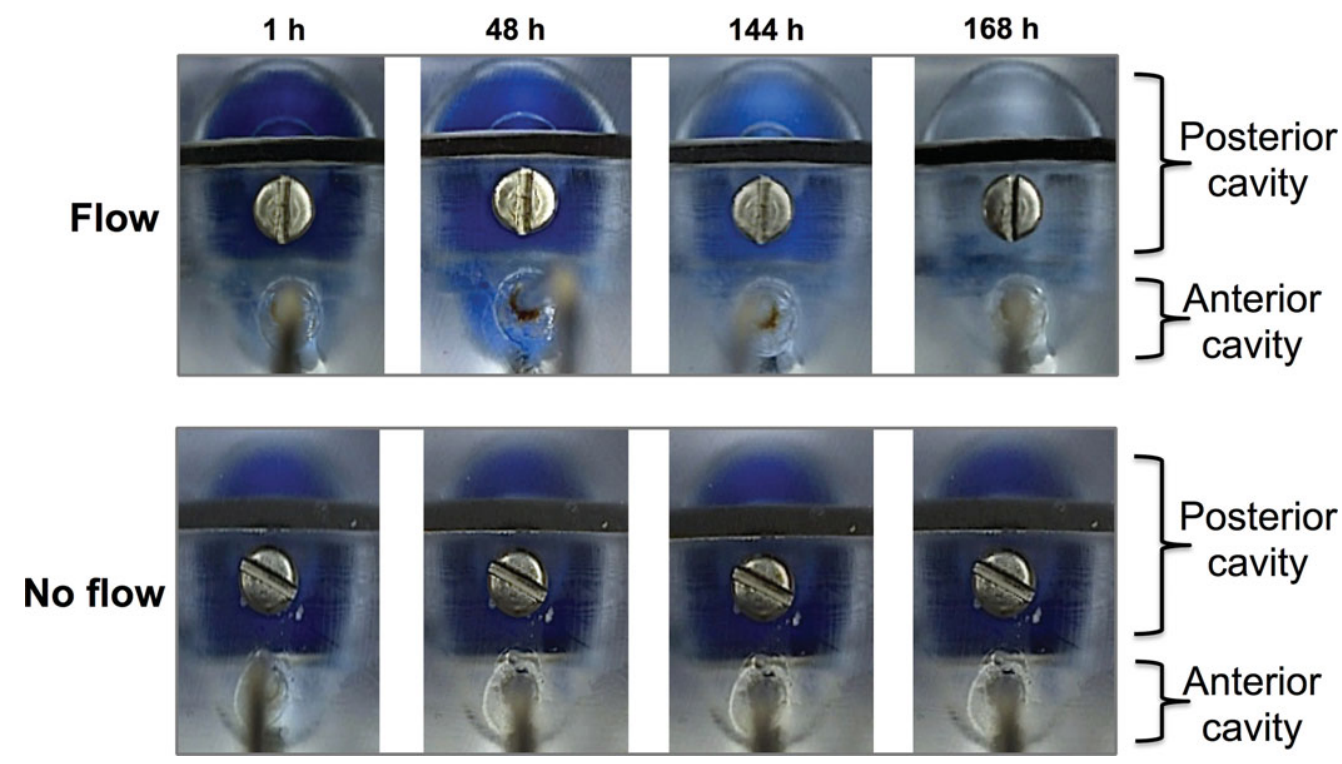

Figure 3. Injection of coomassie blue dye $(100 \mu \mathrm{L}, 1.2 \mathrm{mM})$ into the posterior cavity was monitored over time with (top panel) and without (bottom panel) aqueous flow. The liquid in the model was PBS (pH 7.4). Dye does not pass into the anterior cavity or clear from the model unless there is an aqueous inflow.

and then through the outlet port of the model (Fig. 3, upper panel). When there was no flow (Fig. 3, lower panel), the dye remained concentrated only in the posterior cavity.

These dye experiments broadly mimic mass transfer in the eye that is caused by aqueous flow. When a drug is in the anterior chamber, very little of it will pass into the posterior cavity because of the aqueous outflow. And if a drug is in the posterior cavity, flow is necessary for the drug to clear anteriorly via aqueous outflow. It was conspicuous that the dye did not migrate between the two compartments unless flow was induced (Figs. 2 and 3), so the visking membrane did offer barrier properties to the dye. Coomassie blue has a relatively large molecular weight $(\sim 825 \mathrm{~g} / \mathrm{mol})$ and is partially soluble in water because of its hydrophobic nature. The visking membrane is made from reconstituted cellulose. Water is thought to swell the membrane creating a hydrophilic barrier layer that can act to inhibit the diffusion rate of hydrophobic molecules through the membrane. 58,59

In addition to in vitro permeation models, ${ }^{26,29}$ other in vitro models have been described for the preclinical development of IVT ophthalmic preparations. ${ }^{45,60-63}$ For example, the dissolution of poorly soluble drugs and extended-release tablets ${ }^{62}$ were evaluated using a USP4 dissolution apparatus with a flow through of $1.5 \mathrm{~mL} / \mathrm{min}$ in a chamber of 8-19 mL. ${ }^{64}$ Aspects of drug distribution in the vitreous have been evaluated using a model for saccades (i.e., eye movements), which can influence drug distribution in the vitreous. ${ }^{65}$ This single compartment, nonflow model was used to evaluate dye distribution in glycerol and polyacrylamide gels as vitreous substitutes. ${ }^{66}$ These in vitro models do not mimic the human eye in terms of its compartmentalization, scale, or mass transfer properties because of aqueous flow.

Computational modeling of the eye has also been used to evaluate drug distribution within the vitreous of animals and humans ${ }^{18,67-74}$ after injection or release by implants, ${ }^{75,76}$ and to develop vitreous diffusion IVIVCs. ${ }^{77,78}$ The need to understand how a drug is distributed within the vitreous to ac- cess the retina has been a key driver for many of the studies focused on drug distribution within the posterior segment. However, knowledge of vitreous distribution can only be complete by first determining the residence time of a drug within the vitreous. Any preclinical candidate designed for prolonged action in the posterior cavity must be able to achieve extended PK properties in the presence of intraocular aqueous flow.

\section{Preincubation of the Model with Albumin}

There was a concern that a protein undergoing evaluation would adversely adsorb onto the internal plastic surfaces of the model. The model was preincubated with a $0.1 \%$ albumin solution, and then with the inflow set at $2.0 \mu \mathrm{L} / \mathrm{min}$, bevacizumab was injected $(1.25 \mathrm{mg}$ in $50 \mu \mathrm{L})$ into the posterior cavity of the model.

This experiment was conducted using PBS in the model to allow rapid and complete distribution of bevacizumab throughout the posterior cavity. The use of PBS in the posterior cavity also acted to mimic the reduced viscosity of the vitreous after a vitrectomy. The viscoelastic properties of the vitreous are incompletely understood ${ }^{15,34,79}$ and there are many differences in the composition and microstructure of the vitreous..$^{24,30,36-38}$ As a large molecule, the diffusion of a protein will be faster ${ }^{80}$ and will clear more rapidly from a vitrectomized eye. ${ }^{28,81}$ It was also thought that faster and probably more complete antibody diffusion would occur in a low viscous solution that would make it easier to observe its propensity to adsorb onto the plastic surface.

The observed residence time of bevacizumab from the model after preincubation with albumin followed first-order kinetics and was $1.5 \pm 0.3$ days (Fig. 4a). When the model was not coated with albumin, the bevacizumab clearance half-life was $1.2 \pm 0.1$ days (Fig. 4b). Although this was not significantly different with the clearance half-life when the model was preincubated with albumin, there appeared a less discernable peak concentration, 

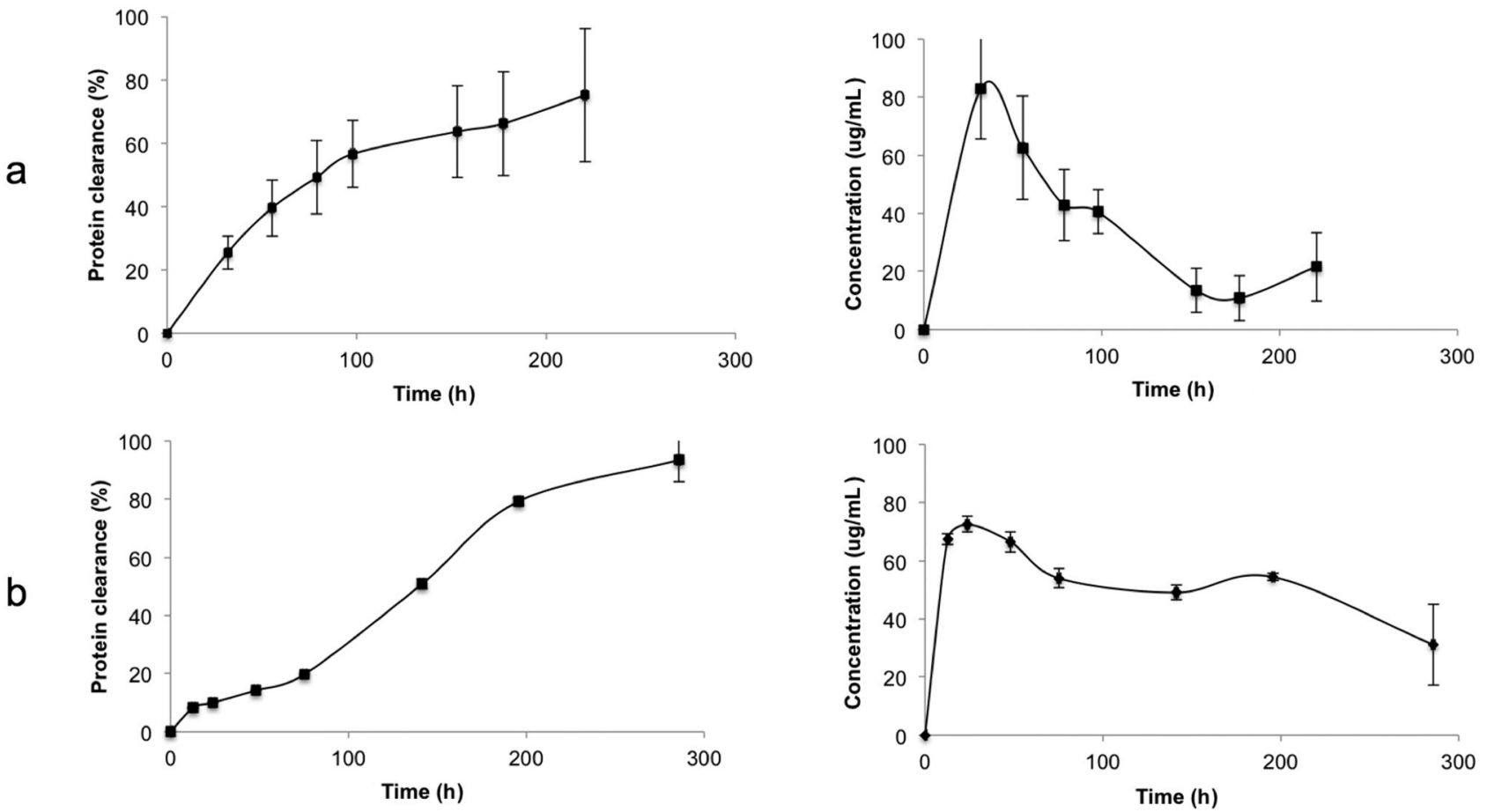

Cumulative bevacizumab clearance

\section{Bevacizumab concentrations}

Figure 4. Release profile of bevacizumab (1.25 mg) using PBS in the vitreal cavity. Half-life values were (a) $1.5 \pm 0.3$ days when the model was preincubated with $0.1 \%$ albumin and (b) $1.2 \pm 0.1$ days without albumin preincubation. The concentration profile for the uncoated model appeared not to have a distinct peak and early time points in the cumulative release profile were consistent with some delay of antibody outflow. These observations suggest that bevacizumab may have interacted with the plastic surface of the uncoated model in phosphate buffer solution. Each time point is shown as mean and standard deviation from three different experiments.

which suggests the bevacizumab reversibly adsorbed onto the plastic surface of the uncoated model. The presence of a peak concentration is characteristic for an intraocular injection ${ }^{73}$ and was more evident when bevacizumab clearance was measured in the albumin-coated model (Fig. 4a). If the model is fabricated from plastic and PBS is used in the posterior cavity, consideration should be made to preincubate with albumin or another blocking protein prior to evaluating a candidate therapeutic protein.

Bevacizumab is a monoclonal antibody that is widely used as an unlicensed, but more cost-effective anti-VEGF medicine ${ }^{3,4}$ that is considered to be clinically equivalent to ranibizumab for the treatment of some indications. ${ }^{82,83}$ It was encouraging that the half-life of $1.5 \pm 0.3$ days from the albumin-coated model (Fig. 4a) is comparable to the half-life of bevacizumab at the same dose in vitrectomized monkey eyes ( $1.5 \pm 0.6$ days; $n=$ $6) .{ }^{84}$ There is a report that the half-life of bevacizumab at a 1.25 $\mathrm{mg}$ dose from a victrectomized human eye of a single patient was 0.7 days. $^{85}$ In nonvitrectomized human eyes at this dose, the half-life of bevacizumab has mean values ranging from 4.9 to 10 days. ${ }^{81,85-88}$ In contrast, the half-life of bevacizumab at this dose is $2.8 \pm 0.6$ days $(n=3)^{89}$ in normal monkey eyes that have an intact vitreous. Although less human data exists for the clearance of bevacizumab in vitrectomized eyes, clearance is expected to be faster than in nonvitrectomized eyes. There is also a significant variation in the half-lives for nonvictrectomized human patients, so the monkey and human data are also significantly different. On the basis of the more complete monkey data, the model could be used to estimate the vitrec- tomized clearance times by using PBS in the vitreous cavity. It is thought this would provide the fastest clearance time possible for a given preclinical formulation.

\section{Clearance Profile of Ranibizumab Using Simulated Vitreous Fluid}

Protein therapeutics will diffuse more slowly in vitreous fluid, which is generally more viscous than PBS. A simulated vitreous liquid was then used in the posterior cavity of the model. Reduced diffusion will prolong the time it takes for the protein to clear from the vitreous cavity. Simulated biological fluids are widely used to mimic aspects of an endogenous fluid during preclinical research. ${ }^{32,90}$ Vitreous substitutes are also widely used, both clinically and for preclinical research. ${ }^{91,92}$ We used a simulated vitreous fluid prepared from HA and agar ${ }^{56}$ that had a dynamic viscosity of approximately $0.6 \mathrm{~Pa} \cdot \mathrm{s}$, which is comparable to human vitreous $(\sim 0.5 \mathrm{~Pa} \cdot \mathrm{s}) .{ }^{93}$ Initial experiments established that none of the components of the simulated vitreous diffused into the anterior cavity of the model and that the simulated vitreous maintained its viscosity over time $(\sim 2-$ 3 weeks). No substrates were observed in the outflow unless ranibizumab was first injected.

Ranibizumab was then injected into the vitreous cavity of the model using the usual clinical dose $(0.5 \mathrm{mg}, 50 \mu \mathrm{L})$. The ranibizumab clearance half-life in the model followed firstorder kinetics and was $8.1 \pm 3.1$ days (Fig. 5a), which is similar to the half-life in humans at this dose $\left(\sim 7.2^{94}\right.$ and $9.0^{95}$ days $)$. Using simulated vitreous provides the means to estimate the time needed for a therapeutic protein to clear via the aqueous 

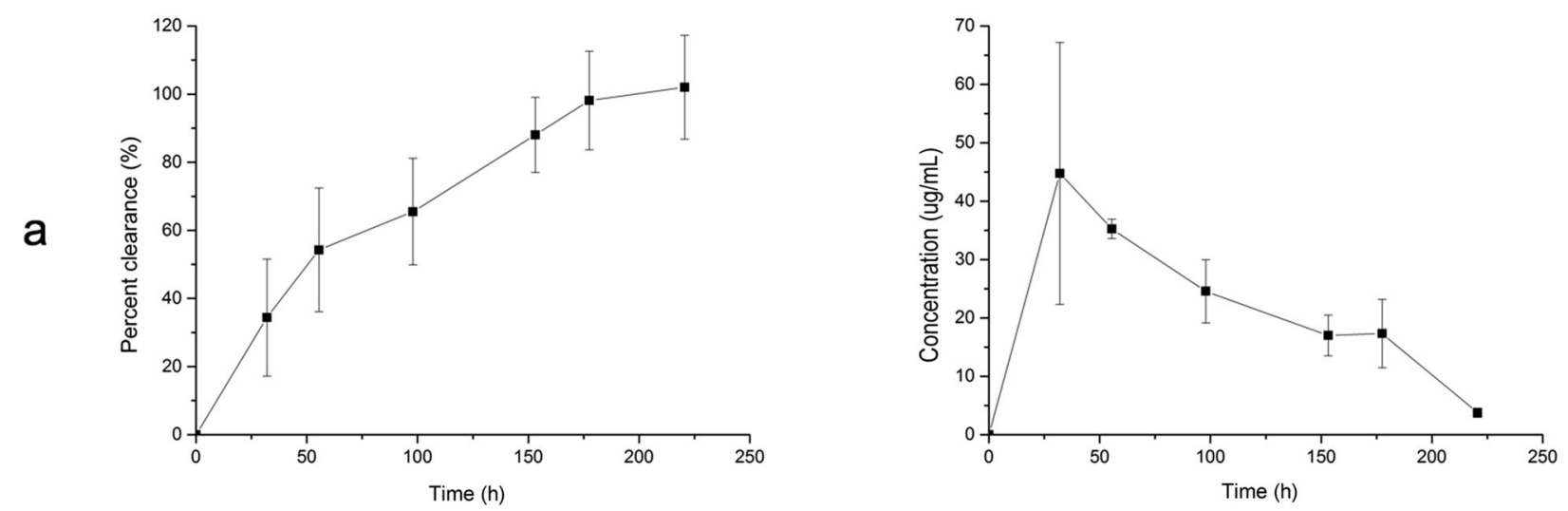

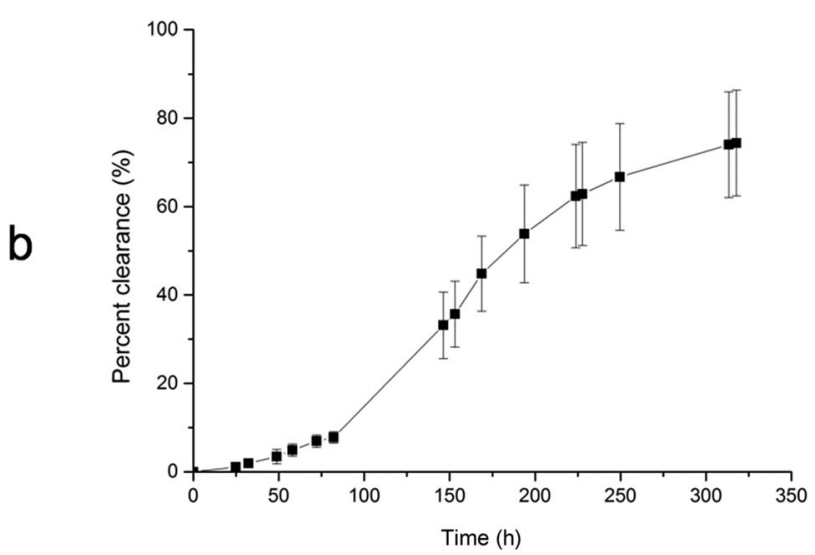

Cumulative ranibizumab clearance

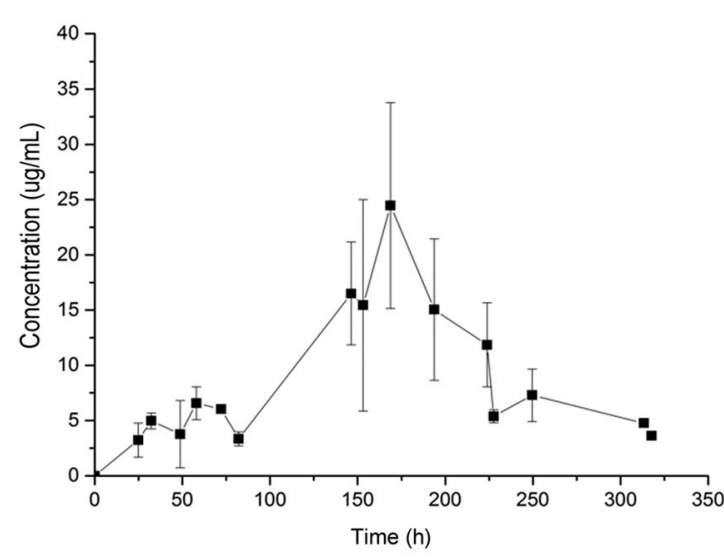

\section{Ranibizumab concentrations}

Figure 5. Release profiles and outflow concentrations of ranibizumab (0.5 mg) after injection into the posterior cavity. The half-life values were (a) $1.5 \pm 0.6$ days with PBS and (b) $8.0 \pm 3.1$ days with simulated vitreous in the posterior cavity. The release profile from simulated vitreous was similar to that observed for humans. Each time point is shown as mean and standard deviation from three different experiments.

outflow pathway from a human eye. When PBS was used in the posterior cavity, the clearance half-life of ranibizumab was $1.5 \pm 0.6$ days (Fig. 5b). This was comparable to bevacizumab (Fig. 4a). When the model was pre-incubated with albumin and then rinsed, no protein was observed from the outflow. Protein was only observed when the sample, i.e. ranibizumab, was injected into the posterior cavity of the model.

The visking membrane had a molecular weight cut off value of $12-14 \mathrm{kDa}$. This refers to the smallest number average molecular weight of a globular macromolecule that will be about $90 \%$ retained when dialyzed overnight, ${ }^{96}$ although there are no strict specification standards. ${ }^{55}$ It was anticipated that with experiments lasting several days to weeks, that passage through the membrane of small amounts of molecules with larger molecular weight would be possible. This is what was observed for both the ranibizumab and bevacizumab experiments (Figs. 4 and 5). It was also necessary for the membrane to ensure the simulated vitreous solution remained in the posterior cavity without allowing the gelled material to pass into the anterior cavity. The simulated vitreous should be made using very highmolecular-weight gelling components that form a stable viscous solution.
As a Fab, ranibizumab $(\sim 48 \mathrm{kDa})$ is about $1 / 3$ the molecular weight of bevacizumab $(\sim 150 \mathrm{kDa})$, which is a full monoclonal antibody. In humans, these molecules display comparable mean half-lives with a similar therapeutic effect. ${ }^{21,86,94}$ The half-lives for ranbizumab span from about 7.2 to 9.0 days and for bevacizumab, the range is about $6.7-10.0$ days. ${ }^{81,85-88}$ As mentioned, these half-lives can be reduced because of medical conditions such as vitrectomy and retinal detachment. ${ }^{97}$ The usual clinical dose for ranibizumab $(0.5 \mathrm{mg})$ is about $20 \%$ more than bevacizumab $(1.25 \mathrm{mg})$ on a molar basis. Of the other biologics registered for ophthalmic use by IVT injection, ${ }^{1}$ there is no reported human half-life data for the Fc fragment fusion (alfibercept, $\sim 115 \mathrm{kDa}$ ), ${ }^{1,81}$ but the PEGylated-aptamer (Pegaptanib, $\sim 50 \mathrm{kDa}$ ) displays a mean half-life of about 78 days for a IVT dose of $0.3 \mathrm{mg}$ as determined by plasma measurements. ${ }^{98}$ Although the half-life of Pegaptanib is essentially the same as ranibizumab, its dose is about $60 \%$ of that is used for ranibizumab on a molar basis. Increasing the dose of Pegaptanib by 10 times of the US FDA-approved dose to 3.0 mg only increases the half-life to about $10( \pm 4)$ days. ${ }^{99,100}$

These observations suggest that there is probably a "molecular weight threshold" after which most proteins and 
macromolecular drugs will display comparable half-lives in the posterior cavity due to clearance by the aqueous outflow pathway. New strategies are being developed to increase the vitreous resident times of macromolecular drugs. ${ }^{7,10,19,34,101-103}$ Some of these strategies may employ the use of implants (for example) where a release or dissolution step is required prior to clearance of the protein therapeutic. It is for these new strategies that we believe our model will find real utility in preclinical research. The strategy to increase the dose of a molecule as a means to increase its "therapeutic tail," which is used with aflibercept, can also be evaluated in a realistic 2-compartment outflow model such as the PK-Eye. As more stable protein therapeutics are developed, much higher concentrated doses may be possible where exploitation of the therapeutic tail is difficult to evaluate in an animal model simply because of the generation of ADAs.

The need during preclinical research to obtain reliable pharmacokinetic information using animal models alone for protein therapeutics cannot be adequately met. The use of our model will avoid the problems associated with ADAs. ${ }^{39-43}$ The model also avoids the need to consider the anatomical differences ${ }^{28,33-35}$ that exist between animal and human eyes. For example, globe sizes of the rabbit (New Zealand white) and monkey (cynomolgus) are similar, but the relative sizes of the anterior chamber and lens of the rabbit are much larger than the monkey. ${ }^{33}$ The rabbit vitreous is about $50 \%$ the size of the monkey vitreous (and about 30\%-40\% that of the human vitreous). But the aqueous flow of the rabbit $\left(\sim 2.0 \mathrm{~L} / \mathrm{min}^{104}\right)$ and monkey $\left(\sim 2.8 \mathrm{~L} / \mathrm{min}^{105}\right)$ are similar to that of the human. Although clearance of ranibizumab will be primarily driven by its diffusion through the vitreous, ${ }^{28}$ its clearance should be faster in the rabbit (less vitreous, larger anterior cavity, shorter diffusion path). However, the half-life of ranibizumab $(0.5 \mathrm{mg})$ from the rabbit and monkey are about the same, being about 2.8-2.9 days ${ }^{22,106,107}$ and about 3 days, ${ }^{35}$ respectively. Even though the monkey eye is more similar to the human eye than is the rabbit eye ${ }^{33}$ the half-life for IVT-injected ranibizumab $(0.5 \mathrm{mg})$ from the monkey is much less than that observed in humans $\left(\sim 7.2^{94}\right.$ and $9.0^{95}$ days).

Although three of the four clinically used macromolecular therapeutics broadly display similar mean half-lives in humans, there is still range of clearance times that is indicative of how intraocular pharmacokinetics can vary in human eyes that are being treated. This variation may be because of how the IVT injection procedure is conducted, ${ }^{28,108,109}$ but more often there are complicating medical conditions ${ }^{86,110,111}$ in patients that require IVT injections that could facilitate greater RCS uptake of nonpermeable molecules. There are also variations in vitreous composition ${ }^{37}$ that can influence flow in the posterior chamber of human eyes ${ }^{68,112}$ where aqueous outflow through the retina may increase. ${ }^{30}$ Variations in the vitreous occur because of (1) age (i.e., liquefaction), ${ }^{24,28,38}$ (2) whether a vitrectomy has been performed, and (3) due to the nature of the medical condition afflicting the eye. For example, small breaks in the inner-limiting membrane (ILM) ${ }^{113,114}$ can cause retinal uptake of non-RCS permeable molecules such as therapeutic proteins. ${ }^{21,87,110,111,115}$ The intact ILM that is between the vitreous and retina can act as a barrier for macromolecules to the retina. ${ }^{7,34}$ The pharmacokinetics of antibodies can further vary because of the presence of Fc receptors in the retinal tissue. ${ }^{115-117}$ Although some posterior aqueous outflow occurs through the retina, the relative amount may be higher in an- imal models than in humans ${ }^{17}$ and radiolabelled ranibizumab can be detected within the retina of the rabbit. ${ }^{118}$ However, quantifying the total dose that may clear through the retina ${ }^{119}$ or extrapolating data for retinal uptake from an animal model after IVT administration is not yet possible. The use of the model with PBS in the vitreous cavity can provide data for the fastest vitreous clearance time to be expected for a preclinical candidate. If considered along with the clearance times obtained with simulated vitreous, it will be possible to obtain minimum and maximum estimates for posterior cavity clearance times very early in preclinical research.

It is not possible with in vivo animal studies to mimic the wide range of conditions encountered in human eyes that may cause pharmacokinetic variation. For example, ranibizumab (and bevacizumab) clearance from vitrectomized rabbit eyes is about the same ${ }^{107}$ or at best slightly reduced compared with nonvitrectomized rabbit eyes. ${ }^{106}$ This may be because of the large rabbit lens making it difficult to remove a high enough proportion of the vitreous. ${ }^{107,109}$ As longer-lasting preparations are developed, differences in human ocular pharmacokinetics will persist to obscure clinical outcomes. It is important in preclinical research to obtain robust PK data based on the aqueous outflow pathway because it appears to change less than RCS pathways for many of the intraocular diseases that require treatment by IVT injections. It is possible with our model to obtain good estimates of the upper limit for clearance early in preclinical studies. The many medical conditions that contribute to accelerate clearance times can then be accounted for to estimate the different clearance times that might occur clinically. ${ }^{120}$ Furthermore, as longer-lasting therapeutic protein preparations are developed, the use of our outflow model will allow for easy sampling to evaluate protein stability that will be important for preparations designed to last 2-3 months inside the vitreous cavity.

\section{Clearance Profile of TA Suspension (Kenalog ${ }^{\circledR}$ )}

The clinical use of steroid implants (e.g., Ozurdex ${ }^{\circledR}$ and Iluvien ${ }^{\circledR}$ ) that release drug over several months into the vitreous are examples of IVT implants ${ }^{19}$ that may become increasingly more common in the clinic. ${ }^{19,24,34,102,103,121-123}$ Many current implants utilize poorly soluble steroids ${ }^{124}$ so the nonsink conditions of the posterior cavity can be exploited to prolong the vitreous resident time. Steroids tend to be lipophilic and permeable, and so a significant amount of material solubilized in the vitreous would be expected to clear by both RCS and anterior outflow pathways. Once a permeable, low-molecularweight molecule is solubilized in the vitreous, clearance would be expected to be relatively quick. ${ }^{18,24,27,28}$ For example, the halflife of intravitreally injected dexamethasone phosphate, which is water soluble, is $3.48 \mathrm{~h}^{27}$

Prior to the development of implants, the IVT injection of a suspension of a poorly soluble drug such as TA $\left(\text { Kenalog }^{\circledR}\right)^{125,126}$ was the best way to clinically prolong the presence of a drug in the vitreous cavity. TA solubility is in the range of approximately $21-30 \mu \mathrm{g} / \mathrm{mL}$ depending on solution media and temperature $\left(25^{\circ} \mathrm{C}-37^{\circ} \mathrm{C}\right) .{ }^{127,128} \mathrm{Kenalog}^{\circledR}$ is the most commonly used TA preparation and has long been used for ophthalmic conditions ${ }^{125,126,129}$; however, there are other, preservative-free, TA formulations available that include Triesence ${ }^{\circledR}$ (Alcon) and Trivaris ${ }^{\circledR}$ (Allergan). ${ }^{129}$ 

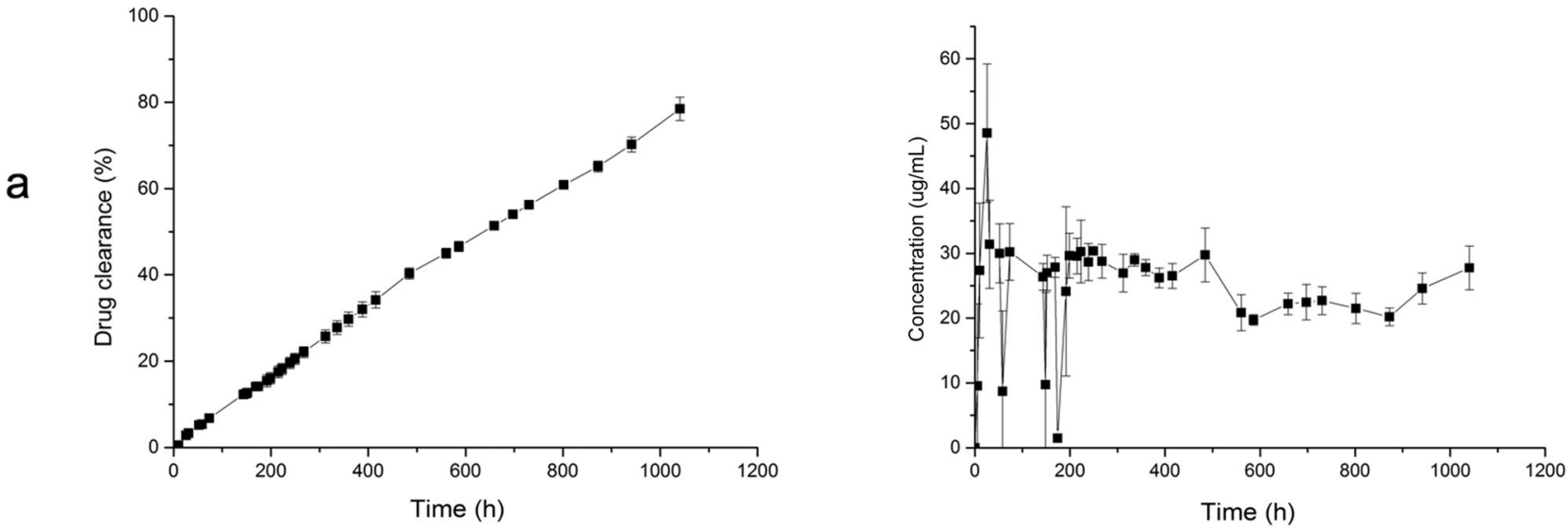

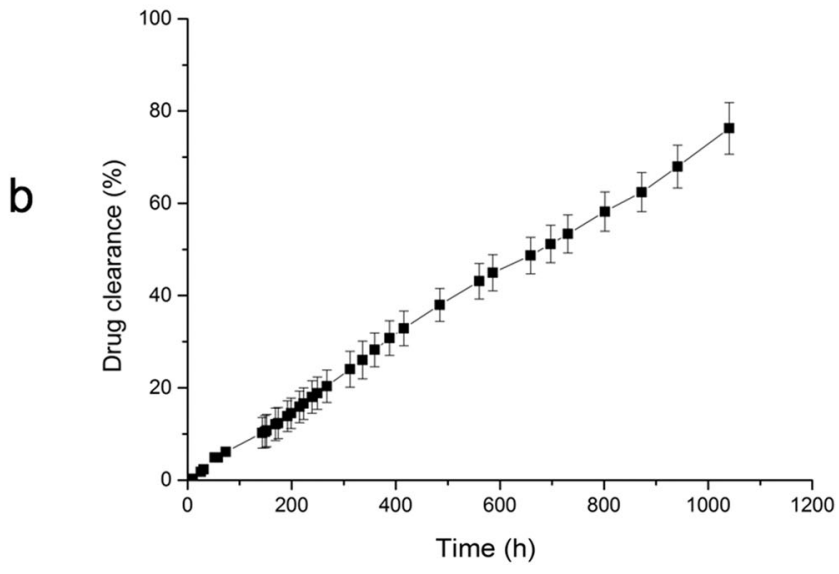

Cumulative TA clearance

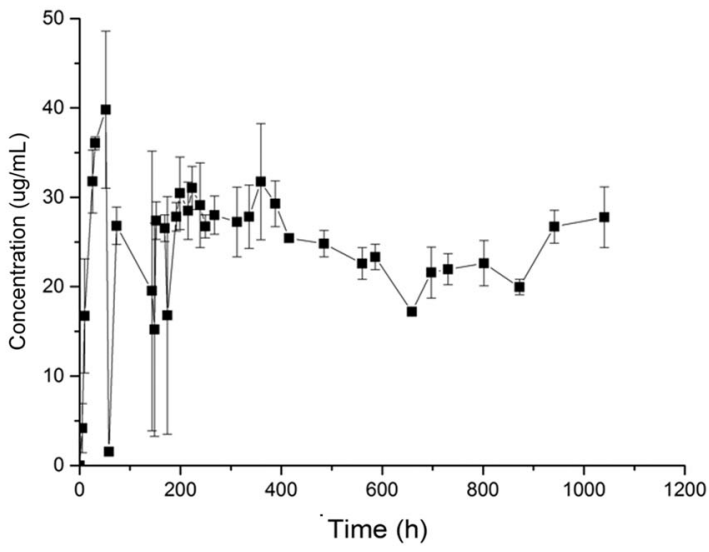

TA concentration

Figure 6. Release profiles and outflow concentrations of TA (Kenalog ${ }^{\circledR}, 4.0 \mathrm{mg}$ ) injected into the posterior cavity at $37^{\circ} \mathrm{C}$. The half-life values were (a) $26.1 \pm 0.8$ days with PBS and (b) $27.8 \pm 3.4$ days with simulated vitreous in the posterior cavity. The solubility limited concentration profile was constant and about the same for PBS and the simulated vitreous. This profile is as expected for a dissolving solid or eluting implant in the vitreous cavity, which acts a single nonsink compartment with liquid out flow. Each time point is shown as mean and standard deviation from three different experiments.

Triamcinolone acetonide (Kenalog ${ }^{\circledR}, 4.0 \mathrm{mg}$ in $100 \mu \mathrm{L}$ ) was injected into the posterior cavity of the model, which was heated to $37^{\circ} \mathrm{C}$. The dissolution rate of the TA suspension is solubility controlled in the total liquid volume of the model and a near constant-release concentration $(\sim 25-30 \mu \mathrm{g} / \mathrm{mL})$ in both PBS and simulated vitreous was observed (Fig. 6). The clearance half-life of TA from the model was in the range of $26-28$ days.

The mean half-life in humans for the IVT administration of TA at the same dose spans $15.4^{130}-18.6$ days. ${ }^{131}$ This clearance time is faster than what was observed in the model because of contributing clearance through RCS pathways. RCS permeable molecules once in solution will clear through both RCS and anterior outflow pathways. Although active transport by the RCS can be significant for some molecules, ${ }^{72}$ our model will provide an estimate of the upper time period for clearance. The model can be used to estimate drug release from implants or the dissolution of suspensions as a first step in their clearance. This will often be the rate-limiting step that defines the overall clearance time of a candidate preparation. Once the active is in solution, the model has the ca- pacity to provide a good estimate of clearance by the anterior outflow route. As for other preparations designed for different modes of administration (e.g., oral, pulmonary), this information can be used with an in vitro ${ }^{26}$ or computational ${ }^{18,29-31}$ permeability model to develop IVIVCs. ${ }^{49,52,53}$ There is intense effort to develop implants and other long-acting preparations from proteins, peptides and nucleotides, $, 10,19,34,101,103$ and possibly other low-molecular-weight substances (e.g., the antiviral agent, Foscarnet ${ }^{18}$ ) that do not clear to a great extent by the RCS. In these cases, the preclinical use of our model would be expected to provide good estimates of useful clearance times.

\section{CONCLUSIONS}

The PK-Eye is a novel pharmacokinetic in vitro model designed for use during preclinical studies to accelerate the development of longer-lasting therapeutic dosage forms that are needed to treat chronic blinding conditions. Our low-cost, two compartment in vitro model is scaled to the human eye and the model mimics the mass transfer characteristics caused by anterior 
aqueous outflow. Therapeutic proteins are large hydrophilic molecules, so they are expected to clear primarily by aqueous outflow pathways. The formation of ADAs in animals in response to human therapeutic proteins and the anatomical differences in animal models make it difficult to correlate clearance profiles with that expected from human eyes. Animal studies also tend to be expensive with a large degree of variation because of the range of experimental protocols that are followed. Ethically, animal experimentation should be minimized when possible, especially when providing limited information.

Dye validation studies and clearance studies utilizing the model in different configurations (e.g., use of either PBS or simulated vitreous) indicate that relevant clearance profiles can be obtained using the model for both proteins and poorly soluble drugs injected as a suspension, or potentially formulated as an implant. Release of an active from an implant or its dissolution from a particulate or suspension will often be the rate-limiting step that defines the overall clearance time of a candidate preparation.

Obtaining PK data for molecules that clear predominantly by the aqueous outflow pathway is important because characteristics of aqueous outflow appear to change less than the permeability properties of the tissues at the back of eye. As longer-lasting preparations are developed, differences in human ocular pharmacokinetics will persist to obscure clinical outcomes. It is possible with our model to obtain good estimates of the maximum and minimum vitreous clearance times early in preclinical studies. This will allow faster optimization cycles during early preclinical studies while avoiding the needless use of animal models until absolutely necessary. Our model can be used with other in vitro or computational permeability models to develop IVIVCs that include RCS clearance pathways. This is analogous to strategies that are used to develop new dosage forms for oral and pulmonary administration. Our in vitro model can easily be used to evaluate protein function and stability. This is difficult to accomplish using animal models and is especially important for dosage forms that have longer clearance times that could extend over a 2-3-month period. Our studies show the PK-Eye model has many of the features needed to become a practical in vitro model with the capacity to contribute to research efforts focused on the development of new ophthalmic medicines.

\section{ACKNOWLEDGMENTS}

We are grateful for funding from the National Institute of Health Research (NIHR) Biomedical Research Centre at Moorfields Eye Hospital NHS Foundation Trust and UCL Institute of Ophthalmology, Moorfields Special Trustees, the Helen Hamlyn Trust (in memory of Paul Hamlyn), Medical Research Council, Fight for Sight and Freemasons Grand Charity. S.A. gratefully acknowledges funding from the UCL Overseas Research Student Fund. S.B. is also grateful for funding from the UK Engineering \& Physical Sciences Research Council (EPSRC) for the EPSRC Centre for Innovative Manufacturing in Emergent Macromolecular Therapies. Financial support from the consortium of industrial and governmental users for the EPSRC Centre is also acknowledged. We thank Mr John Frost for all his advice and help to fabricate prototypes of the PK-Eye.

\section{REFERENCES}

1. Penedones A, Mendes D, Alves C, Marques FB. 2014. Safety monitoring of ophthalmic biologics: A systematic review of pre- and postmarking safety data. J Ocul Pharmacol Ther 30(9):729-751.

2. Jager RD, Aiello LP, Patel SC, Cunningham ET. 2004. Risks of intravitreous injection: A comprehensive review. Retina 24:676-698.

3. Elshout M, van der Reis MI, Webers CA, Schouten JS. 2014. The costutility of aflibercept for the treatment of age-related macular degeneration compared to bevacizumab and ranibizumab and the influence of model parameters. Graefes Arch Clin Exp Ophthalmol 252:1911-1920. 4. Kwong TQ, Mohamed M. 2014. Anti-vascular endothelial growth factor therapeis in ophthalmology: Current use, controversies and the future. Br J Clin Pharmacol 78(4):699-706.

5. de Oliveira Dias JR, Rodrigues EB, Maia M, Magalhães O, Penha FM, Farah ME. 2011. Cytokines in neovascular age-related macular degeneration: Fundamentals of targeted combination therapy. $\mathrm{Br} \mathrm{J}$ Ophthalmol 95:1631-1637.

6. Rodrigues EB, Farah ME, Maia M, Penha FM, Regatieri C, Melo GB, Pinheiro MM, Zanetti CR. 2009. Therapeutic monoclonal antibodies in ophthalmology. Prog Retinal Eye Res 28:117-144.

7. El-Sanharawi M, Kowalczuk L, Touchard E, Omri S, de Kozak Y, Behar-Cohen F. 2010. Protein delivery for retinal diseases: From basic considerations to clinical applications. Prog Retinal Eye Res 29:443465 .

8. Yasukawa T, Tabata Y, Kimura H, Ogura Y. 2011. Ocular drug delivery of bioactive proteins. Expert Rev Ophthalmol 6:657-667.

9. Saadoun D, Bodaghi B, Bienvenu B, Wechsler B, Sene D, Trad S, Abad S, Cacoub P, Kodjikian L, Seve P. 2013. Biotherapeies in inflammatory ocular disorders: Interferons, immunoglobulins, monoclonal antibodies. Autoimmun Rev 12:774-783.

10. Kim YC, Chiang B, Wu X, Prausnitz MR. 2014. Ocular delivery of macromolecules. J Control Release 190:172-181.

11. Schweizer D, Serno T, Goepferich A. 2014. Controlled release of therapeutic antibody formats. Eur J Pharm Biopharm 88(4):291309.

12. Brubaker RF. 1982. The flow of aqueous humor in the human eye. Trans Am Ophthalmol Soc 80:391-474.

13. Toris CB, Yablonski ME, Wang YL, Camras CB. 1999. Aqueous humor dynamics in the aging human eye. Am J Ophthalmol 127:407412.

14. Maurice DM. 2001. Practical issues in intravitreal drug delivery. J Ocul Pharmacol Ther 17(4):393-401.

15. Siggers JH, Ethier C. 2012. Fluid mechanics of the eye. Annu Rev Fluid Mech 44:347-372.

16. Ethier C, Johnson M, Ruberti J. 2004. Ocular biomechanics and biotransport. Annu Rev Biomed Eng 6:249-273.

17. Hayreh SH. 1966. Posterior drainage of the intraocular fluid from the vitrous. Exp Eye Res 5:123-144.

18. Haghjou N, Abdekhodaie MJ, Cheng Y-L. 2013. Retina-choroidsclera permeability for ophthalmic drugs in the vitreous to blood direction: Quantitative assessment. Pharm Res 30:41-59.

19. Choonara YE, Pillay V, Danckwerts MP, Carmichael TR, du Toit LC. 2010. A review of implantable intravitreal drug delivery technologies for the treatment of posterior segment eye diseases. J Pharm Sci 99:2219-2239.

20. Cunha-Vaz JG. 1997. The blood-ocular barriers: Past, present, and future. Doc Ophthalmol 93:149-157.

21. Krohne TU, Eter N, Holz FG, Meyer CH. 2008. Intraocular pharmacokinetics of bevacizumab after a single intravitreal injection in humans. Am J Ophthalmol 146:508-512.

22. Bakri SJ, Snyder MR, Reid JM, Pulido JS, Ezzat MK, Singh RJ. 2007. Pharmacokinetics of intravitreal ranibizumab (Lucentis). Ophthalmology 114:2179-2182.

23. Kim H, Csaky K, Chan C, Bungay P. 2006. The pharmacokinetics of rituximab following an intravitreal injection. Exp Eye Res 82:760766. 
24. Thrimawithana T, Young S, Bunt C. 2011. Drug delivery to the posterior segment of the eye. Drug Discov Today 16:270-277.

25. Urtti A. 2006. Challenges and obstacles of ocular pharmacokinetics and drug delivery. Adv Drug Deliv Rev 58:1131-1135.

26. Pitkänen L, Ranta V-P, Moilanen H, Urtti A. 2005. Permeability of retinal pigment epithelium: Effects of permeant molecular weight and lipophilicity. Invest Ophthalmol Visual Sci 46:641-646.

27. Kwak HW, Amico DJD. 1992. Evaluation of the retinal toxicity and pharmacokinetics of dexamethasone after intravitreal injection. Arch Ophthalmol 110:259-266.

28. Laude A, Tan LE, Wilson CG, Lascaratos G, Elashry M, Aslam T, Patton N, Dhillon B. 2010. Intravitreal therapy for neovascular agerelated macular degeneration and inter-individual variations in vitreous pharmacokinetics. Prog Retinal Eye Res 29:466-475.

29. Durairaj C, Shah JC, Senapati S, Kompella UB. 2009. Prediction of vitreal half-life based on drug physicochemical properties: Quantitative structure-pharmacokinetic relationships (QSPKR). Pharm Res 26(5):1236-1260.

30. Krishnamoorthy MK, Park J, Augsburger JJ, Banerjee RK. 2008. Effect of retinal permeability, diffusivity, and aqueous humor hydrodynamics on pharmacokinetics of drugs in the eye. J Ocul Pharmacol Ther 24:255-267.

31. Kidron H, Del Amo EM, Vellonen K-S, Urtti A. 2012. Predicition of the vitreal half-life of small molecular drug-like compounds. Pharm Res 29:3302-3311.

32. Pepić I, Lovrić J, Cetina-Čižmek B, Reichl S, Filipović-Grčić J. 2014. Toward the practical implementation of eye-related bioavailability prediction models. Drug Discov Today 19:31-44.

33. Short BG. 2008. Safety evaluation of ocular drug delivery formulations: Techniques and practical considerations. Toxicol Pathol 36:4962.

34. Thakur SS, Barnett NL, Donaldson MJ, Parekh HS. 2014. Intravitreal drug delivery in retinal disease: Are we out of our depth? Expert Opin Drug Deliv 11:1575-1590.

35. Gaudreault J, Fei D, Rusit J, Suboc P, Shiu V. 2005. Preclinical pharmacokinetics of Ranibizumab (rhuFabV2) after a single intravitreal administration. Invest Ophthalmol Visual Sci 46:726-733.

36. Schaal KB, Pang CE, Pozzoni MC, Engelbert M. 2014. The premacular bursa's shape revealed in vivo by swept-source optical coherence tomography. Ophthalmology 121:1020-1028.

37. Fowlks WL. 1963. Meridional flow from the corona ciliaris through the pararetinal zone of the rabbit vitreous. Invest Ophthalmol 2:63-71. 38. Bishop PN. 2000. Structural macromolecules and supramolecular organisation of the vitreous gel. Prog Retinal Eye Res 19:323-344.

39. Vugmeyster Y, Xu X, Theil F-P, Khawli La, Leach MW. 2012. Pharmacokinetics and toxicology of therapeutic proteins: Advances and challenges. World J Biol Chem 3:73-92.

40. Brinks V, Jiskoot W, Schellekens H. 2011. Immunogenicity of therapeutic proteins: The use of animal models. Pharm Res 28:2379-2385. 41. Tamilvanan S, Raja NL, Sa B, Basu SK. 2010. Clinical concerns of immunogenicity produced at cellular levels by biopharmaceuticals following their parenteral administration into human body. J Drug Target 18:489-498.

42. Wang W, Singh SK, Li N, Toler MR, King KR, Nema S. 2012. Immunogenicity of protein aggregates-concerns and realities. Int J Pharm 431:1-11.

43. Brinch KS, Frimodt-Møller N, Høiby N, Kristensen H-H. 2009. Influence of antidrug antibodies on plectasin efficacy and pharmacokinetics. Antimicrob Agents Chemother 53:4794-4800.

44. Shankar G, Shores E, Wagner C, Mire-Sluis A. 2006. Scientific and regulatory considerations on the immunogenicity of biologics. Trends Biotechnol 24:274-280.

45. Ohtori A, Tojo K. 1994. In vivo/in vitro correlation of intravitreal delivery of drugs with the help of computer simulation. Biol Pharm Bull 17(2):283-290.

46. Barat A, Ruskin HJ, Crane M. 2006. Probabilistic methods for drug dissolution. Part 2. Modelling a soluble binary drug delivery system dissolving in vitro. Simul Model Pract Th 14:857-873.
47. Bonam M, Christopher D, Cipolla D, Donovan B, Goodwin D, Holmes S, Lyapustina S, Mitchell J, Nichols S, Pettersson G, Quale C, Roa N, Singh D, Tougas T, VanOort M, Walther B, Wyka B. 2008. Minimizing variability of cascade impaction measurements in inhalers and nebelizers. AAPS PharmSciTech 9(2):404-413.

48. Agu RU, Ugwoke MI. 2011. In vitro and in vivo test methods for respiratory drug delivery. Expert Opin Drug Deliv 8(1):5769.

49. Jones H, Gardner I, Collard W, Stanley P, Oxley P, Hosea N, Plowchalk D, Gernhardt S, Lin J, Dickins M, Rahavendran S, Jones B, Watson K, Pertinez H, Kumar V, Cole S. 2011. Simulation of human intravenous and oral pharmacokinetics of 21 diverse compounds using physiologically based pharmacokinetic modelling. Clin Pharmacokinet 50(5):331-347.

50. Lave T, Chapman K, Goldsmith P, Rowland M. 2009. Human clearance prediction: Shifting the paradigm. Expert Opin Drug Metab Toxicol 5(9):1039-1048.

51. Rostami-Hodjegan A, Tucker G. 2007. Simulation and prediction of in vivo drug metabolism in human populations from in vitro data. Nat Rev Drug Discov 6:140-148.

52. Longest P, Tian G, Walenga RL, Hindle M. 2012. Comparing MDI and DPI aerosol deposition using in vitro experiments and a new stochoastic individual path (SIP) model of the conducting airways. Pharm Res 29:1670-1688.

53. Sun L, Cun D, Yuan B, Cui H, Xi H, Mu L, Chen Y, Liu C, Wang Z, Fang L. 2012. Formulation and in vitro/in vivo correlation of a drug-in-adhesive transderma patch containing azasetron. J Pharm Sci 101(12):4540-4548.

54. Larsen C, Larsen S. 2009. Role of in vitro release models in formulation development and quality control of parenteral depots. Expert Opin Drug Deliv 6:1283-1295.

55. Ng S-F, Rouse JJ, Sanderson FD, Eccleston GM. 2012. The relevance of polymeric synthetic membranes in topical formulation assessment and drug diffusion study. Arch Pharm Res 35(4):579593.

56. Smerdon D. 2000. Anatomy of the eye and orbit. Curr Anaesth Crit Care 11:286-292.

57. Kummer MP, Abbott JJ, Dinser S, Nelson BJ. 2007. Artificial vitreous humor for in vitro experiments. Proceedings of the International Conference of IEEE Engineering in Medicine and Biology Society. Lyon, France. Accessed on August 23-26, 2007.

58. Reid ML, Brown MB, Moss GP, Jones SA. 2008. An investigation in solvent-membrane interactions when assessing drug release from organic vehicles using regenerated cellulose membranes. J Pharm Pharmacol 60:1139-1147.

59. Fiala S, Brown MB, Jones SA. 2008. An investigation into the influence of binary drug solutions upon diffusion and partition processes in model membranes. J Pharm Pharmacol 60:16151623 .

60. Repetto R, Siggers JH, Stocchino A. 2010. Mathematical model of flow in the vitreous humor induced by saccadic eye rotations: Effect of geometry. Biomech Model Mechanobiol 9:65-76.

61. Loch C, Bogdahn M, Stein S, Nagel S, Guthoff R, Weitschies W, Seidlitz A. 2013. Simulation of drug distribution in the vitreous body after local drug application into intact vitreous body and in progress of posterior vitreous detachment. J Pharm Sci 103:517526.

62. Browne D, Kieselmann S. 2010. Low-level drug release-rate testing of ocular implants using USP apparatus 4 dissolution and HPLC end analysis. Dissolut Technol 17:12-14.

63. Fogli G, Orsi G, De Maria C, Montemurro F, Palla M, Rizzo S, Vozzi G. 2014. New eye phantom for ophthalmic surgery. J Biomed Opt 19:068001.

64. Fotaki N. 2011. Flow-through cell apparatus (USP apparatus 4): Operation and features. Dissolut Technol 18(4):46-49.

65. Repetto R, Stocchino A, Cafferata C. 2005. Experimental investigation of vitreous humour motion within a human eye model. Phys Med Biol 50:4729-4743. 
66. Loch C, Stein S, Nagel S, Seidlitz A, Guthoff R, Weitschies W. 2013. Simulation of the conjunctival and choroidal blood flow using a new multi-layer diffusion cell. Biomed Tech 58:4-5.

67. Fatt I. 1975. Flow and Diffusion in the vitreous body of the eye. Bull Math Biol 37:85-90.

68. Worakul N, Robinson JR. 1997. Ocular pharmacokineticspharmacodynamics. Eur J Pharm Biopharm 44(1627):71-83.

69. Missel PJ. 2002. Hydraulic flow and vascular clearance influences on intravitreal drug delivery. Pharm Res 19:1636-1647.

70. Missel PJ. 2012. Simulating intravitreal injections in anatomically accurate models for rabbit, monkey and human eyes. Pharm Res 29:3251-3272.

71. Stay MS, Xu J, Randolph TW, Barocas VH. 2003. Computer simulation of convective and diffusive transport of controlled-release drugs in the vitreous humor. Pharm Res 20:96-102.

72. Balachandran RK, Barocas VH. 2008. Computer modeling of drug delivery to the posterior eye: Effect of active transport and loss to choroidal blood flow. Pharm Res 25:2685-2696.

73. Park J, Bungay P, Lutz R, Augsburger J, Millard R, Roy A, Banerjee R. 2005. Evaluation of coupled convective-diffusive transport of drugs administered by intravitreal injection and controlled release implant. J Control Release 105:279-295.

74. Kathawate J, Acharya S. 2008. Computational modeling of intravitreal drug delivery in the vitreous chamber with different vitreous substitutes. Int J Heat Mass Transfer 51:5598-5609.

75. Jooybar E, Adbekhodaie MJ, Farhadi F, Cheng Y-L. 2014. Computational modeling of drug distribution in the posterior segment of the eye: Effects of device variables and positions. Math Biosci 225:11-20.

76. Kavousanakis ME, Kalogeropoulos NG, Hatziavramidis DT. 2014. Computational modeling of drug delivery to the posterior eye. Chem Eng Sci 108:203-212.

77. Tojo K, Isowaki A. 2001. Pharmacokinetic model for in vivo/in vitro correlation of intravitreal drug delivery. Adv Drug Deliv Rev 52:17-24. 78. Tojo K. 2004. A pharmacokinetic model for ocular drug delivery. Chem Pharm Bull 52(11):1290-1294.

79. Nickerson CS, Park J, Kornfield JA, Karageozian H. 2008. Rheological properties of the vitreous and the role of hyaluronic acid. J Biomech 41:1840-1846.

80. Xu J, Heys JJ, Barocas VH, Randolph TW. 2000. Permeability and diffusion in vitreous humor: Implications for drug delivery. Pharm Res 17(6):664-670.

81. Krohne TU, Holz FG, Meyer CH. 2014. Pharmakokinetik intravitreal applizierter VEGF-inhibitoren; "pharmacokinetics of intravitreally administered VEGF inhibitors". Ophthalmology 111:113-120.

82. Chakravarthy U, Harding S, Rogers C, Downes S, Lotery A, Wordsworth S, Reeves B. 2012. Ranibizumab versus bevacizumab to treat neovascular age-related macular degeneration: One-year findings from the IVAN randomized trial. Ophthalmology 119:1399_ 1411.

83. Martin D, Maguire M, Fine S, Ying G, Jaffe G, Grunwald J, Toth C, Redford M, Ferris F. 2012. Ranibizumab and bevacizumab for treatment of neovascular age-related macular de- generation: Two-year results. Ophthalmology 119:1388-1398.

84. Kakinoki M, Sawada O, Sawada T, Saishin Y, Kawamura H, Ohji M. 2012. Effect of vitrectomy on aqueous VEGF concentration and pharmacokinetics of bevacizumab in macaque monkeys. Invest Ophthalmol Vis Sci 53:5877-5880.

85. Moisseiev E, Waisbourd M, Ben-Artsi E, Levinger E, Barak A, Daniels T, Csaky K, Loewenstein A, Barequet IS. 2014. Pharmacokinetics of bevacizumab after topical and intravitreal administration in human eyes. Graefes Arch Clin Exp Ophthalmol 252:231-337.

86. Meyer CH, Krohne TU, Holz FG. 2011. Intraocular pharmacokinetics after a single intravitreal injection of $1.5 \mathrm{mg}$ versus $3.0 \mathrm{mg}$ of bevacizumab in humans. Retina 31:1877-1884.

87. Zhu Q, Ziemssen F, Henke-Fahle S, Tatar O, Szurman P, Aisenbrey S, Schneiderhan-Marra N, Xu X, Grisanti S. 2008. Vitreous levels of bevacizumab and vascular endothelial growth factor-A in patients with choroidal neovascularization. Ophthalmology 115:1750-1755.
88. Beer P, Wong S, Hammad A, Falk N, O'Malley M, Khan S. 2006. Vitreous levels of unbound bevacizumab and unbound vascular endothelial growth factor in two patients. Retina 26:871-876.

89. Miyake T, Sawada O, Kakinoki M, Sawada T, Kawamura H, Ogasawara K, Ohji M. 2010. Pharmacokinetics of bevacizumab and its effect on vascular endothelial growth factor after intravitreal injection of bevacizumab in macaque eyes. Invest Ophthalmol Vis Sci 51:1606-1608.

90. Marques MRC, Loebenberg R, Almukainzi M. 2011. Simulated biological fluids with possible application in dissolution testing. Dissolut Technol 18(3):15-28.

91. Kleinberg TT, Tzekov RT, Stein L, Ravi N, Kaushal S. 2011. Vitreous substitutes: A comprehensive review. Surv Ophthalmol 56(4):300 323.

92. Donati S, Caprani SM, Airaghi G, Vinciguerra R, Bartalena L, Testa F, Mariotti C, Porta G, Simonelli F, Azolini C. 2014. Vitreous substitutes: The present and the future. BioMed Res Int 2014(351804):1-12. 93. Soman N, Banerjee R. 2003. Artificial vitreous replacements. BioMed Mater Eng 13:59-74.

94. Krohne TU, Liu Z, Holz FG, Meyer CH. 2012. Intraocular pharmacokinetics of ranibizumab following a single intravitreal injection in humans. Am J Ophthalmol 154:682-686.

95. Xu L, Lu T, Tuomi L, Jumbe N, Lu J, Eppler S, Kuebler P, DamicoBeyer LA, Josbi A. 2013. Pharmacokinetics of ranibizumab in patients with neovascular age-related macular degeneration: A population approach. Invest Ophthalmol Vis Sci 54(3):1616-1624.

96. Haney P, KHerting K, Smith S. Separation characteristics of dialysis membranes. Pierce reviews. Accessed, at: http://www. piercenet.com/previews/2013-articles/separation-characteristicsdialysis-membranes/. Accessed May 2015

97. Stewart MW. 2014. Pharmacokinetics, pharmacodynamics and preclinical characteristics of ophthalmic drugs that bind VEGF. Expert Rev Clin Pharmacol 7(2):167-180.

98. Basile AS, Hutmacher M, Nickens D, Nielsen J, Kowalski K, Whitfield L, Masayo O, Nakane M. 2012. Population pharmacokinetics of Pegaptanib in patients with neovascular, age-related macular degeneration. J Clin Pharmacol 52:1186-1199.

99. Package insert prescribing information. 2011. Pegaptanib sodium injection NDA-21-756/S-018. Reference ID: 3026883.

100. Morjaria R, Chong NV. 2014. Pharmacokinetic evaluation of Pegaptanib octasodium for the treatment of diabetic edema. Expert Opin Drug Metab Toxicol 10(8):1185-1192.

101. Bourges J, Bloquel C, Thomas A, Froussart F, Bochot A, Azan F, Gurny R, BenEzra D, Behar-Cohen F. 2006. Intraocular implants for extended drug delivery: Therapeutic applications. Adv Drug Deliv Rev 58:1182-1202.

102. Lee SS, Hughes P, Ross AD, Robinson MR. 2010. Biodegradable implants for sustained drug release in the eye. Pharm Res 27:20432053.

103. Kang-Mieler JJ, Osswald CR, Mieler WF. 2014. Advances in ocular drug delivery: Emphasis on the posterior segment. Expert Opin Drug Deliv 11(10):1647-1660.

104. McMaster PR, Macri FJ. 1967. The rate of aqueous humor formation in buphthalmic rabbit eyes. Invest Ophthalmol 6:8487.

105. Bartels SP. 1988. Aqueous humor flow measured with fluorophotometry in timolol-treated primates. Invest Ophthalmol Vis Sci 29:1498-1504.

106. Christoforidis JB, Williams MM, Wang J, Jiang A, Pratt C, AbdelRasoul M, Hinkle GH, Knopp MV. 2013. Anatomic and pharmacokinetic properties of intravitreal bevacizumab and ranibizumab after vetrectomy and lensectomy. Retina 33:946-952.

107. Ahn SJ, Ahn J, Park S, Kim H, Hwang DJ, Park HJ, Park JY, Chung JY, Park KH, Woo SJ. 2014. Intraocular pharmacokinetics of ranibizumab in vitrectomized versus nonvitrectomised eyes. Invest Ophthalmol Vis Sci 55(1):567-573.

108. Miura Y, Uematsu M, Teshima M, Suzuma K, Kumagami T, Sasaki H, Kitaoka T. 2011. Injection site and pharmacokinetics 
after intravitreal injection of immunoglobulin G. J Ocul Pharmacol Ther 27(1):35-41.

109. Ahn J, Kim H, Woo SJ, Park JH, Park S, Hwang DJ, Park KH. 2013. Pharmacokinetics of intravitreally injected bevacizumab in vitrectomized eyes. J Ocul Pharmacol Ther 29(7):612-618.

110. Mordenti J, Thomsen K, Licko V, Berleau L, Kahn JW, Cuthbertson Ra, Duenas ET, Ryan aM, Schofield C, Berger TW, Meng YG, Cleland J. 1999. Intraocular pharmacokinetics and safety of a humanized monoclonal antibody in rabbits after intravitreal administration of a solution of a PLGA microsphere formulation. Toxicol Sci 52:101106.

111. Edelhauser HF, Rowe-Rendleman CL, Robinson MR, Dawson DG, Chader GJ, Grossniklaus HE, Rittenhouse KD, Wilson CG, Weber DA, Kuppermann BD, Csaky KG, Olsen TW, Kompella UB, Holers VM, Hageman GS, Gilger BC, Campochiaro PA, Whitcup SM, Wong WT. 2010. Ophthalmic drug delivery systems for the treatment of retinal diseases: Basic research to clinical applications. Invest Ophthalmol Vis Sci 51:5403-5420.

112. Dias CS. 2003. Posterior Segment ocular pharmacokinetics using microdialysis in a conscious rabbit model. Invest Ophthalmol Vis Sci 44:300-305.

113. Mains J, Wilson CG. 2013. The vitreous humor as a barrier to nanoparticle distribution. J Ocul Pharmacol Ther 29:143-150.

114. Wolter JR. 2009. Pores in the internal limiting membrane of the human retina. Acta Ophthalmol 42:971-974.

115. Heiduschka P, Fietz H, Hofmeister S, Schultheiss S, Mack AF, Peters S, Ziemssen F, Niggemann B, Julien S, Bartz-Schmidt KU, Schraermeyer U. 2007. Penetration of bevacizumab through the retina after intravitreal injection in the monkey. Invest Ophthalmol Vis Sci 48:2814-2823.

116. Van Bilsen $K$, van Hagen PM, Bastiaans J, van Meurs JC, Missotten T, Kuijpers RW, Hooijkaas H, Dingjan GM, Baarsma GS, Dik WA. 2011. The neonatal Fc receptor is expressed by human retinal pigment epithelial cells and is downregulated by tumour necrosis factor-alpha. Br J Ophthalmol 95:864-868.

117. Niu N, Zhang J, Sun Y, Wang S, Sun Y, Korteweg C, Gao W, Gu J. 2011. Expression and distribution of immunoglobulin G and its receptors in an immune privileged site: The eye. Cell Mol Life Sci 68:24812492 .

118. Gaudreault J, Fei D, Beyer JC, Ryan A, Rangell L, Shiu V, Damico La. 2007. Pharmacokinetics and retinal distribution of ranibizumab, a humanized antibody fragment directed against VEGFA, following intravitreal administration in rabbits. Retina 27:1260 1266 .
119. Shahar J, Avery RL, Heilweil G, Barak A, Zemel E, Lewis GP, Johnson PT, Fisher SK, Perlman I, Loewenstein A. 2006. Electrophysiologic and retinal penetration studies following intravitreal injection of bevacizumab (Avastin). Retina 26:262-269.

120. Basile A, Johnson T, Klamerous K, Zhou D, Sultan M, Amantea M, Nickens D. 2014. Integrating disease progression models, non-clinical pharmacokinetic data and treatment response endpoints to optimize intravitreal dosing regimens. Int $\mathrm{J}$ Clin Pharmacol Ther 52(7):574586.

121. Christoforidis JB, Chang S, Jiang A, Wang J, Cebulla CM. 2012. Intravitreal devices for the treatment of vitreous inflammation. Mediators Inflamm 2012:126463.

122. Gilger BC, Abarca EM, Salmon JH, Patel S. 2013. Treatment of acute posterior uveitis in a porcine model by injection of triamcinolone acetonide into the suprachoroidal space using microneedles. Invest Ophthalmol Vis Sci 54:2483-2492.

123. Cima MJ, Lee H, Daniel $\mathrm{K}$, Tanenbaum LM, Mantzavinou A, Spencer KC, Ong Q, Sy JC, Santini J, Schoellhammer CM, Blankschtein D, Langer RS. 2014. Single compartment drug delivery. J Control Release 190:157-171.

124. Cabrera M, Yeh S, Albini TA. 2014. Sustained-release corticosteroid options. J Ophthalmol. 2014: 164692.

125. Jermak CM, Dellacroce JT, Heffez J, Peyman GA. 2007. Triamcinolone acetonide in ocular therapeutics. Surv Ophthalmol 52:503-522. 126. Zacharias LC, Lin T, Migon R, Ghosn C, Orilla W, Feldmann B, Ruiz G, Li Y, Burke J, Kuppermann BD. 2013. Assessment of the differences in pharmacokinetics and pharmacodynamics between four distinct formulations of triamcinolone acetonide. Retina 33:522-531.

127. Block LH, Patel RN. 1973. Solubility and dissolution of tiramcinolone acetonide. J Pharm Sci 62(4):617-621.

128. Behl CH, Block LH, Borke ML. 1976. Aqueous solubility of 14Ctriamcinolone acetonide. J Pharm Sci 65(3):429-430.

129. Yilmaz T, Cordero-Coma M, Federici TJ. 2011. Pharmacokinetics of triamcinolone acetonide for the treatment of macular edema. Expert Opin Drug Metab Toxicol 7:1327-1335.

130. Audren F, Tod M, Massin P, Benosman R, Haouchine B, Erginay A, Caulin C, Gaudric A, Bergmann J-F. 2004. Pharmacokineticpharmacodynamic modeling of the effect of triamcinolone acetonide on central macular thickness in patients with diabetic macular edema. Invest Ophthalmol Vis Sci 45:3435-3441.

131. Beer PM, Bakri SJ, Singh RJ, Liu W, Peters GB, Miller M. 2003. Intraocular concentration and pharmacokinetics of triamcinolone acetonide after a single intravitreal injection. Ophthalmology 110:681686. 